\title{
Reflexiones para el diálogo. Comentarios al libro La Colombia del posacuerdo: retos de un país excluido por el conflicto armado
}

García, R., Wilches, J., Guerrero, H., y Hernández, M. (2018). La Colombia del Posacuerdo: retos de un país excluido por el conflicto armado. Bogotá, D.C.: Editorial Universidad Distrital Francisco José de Caldas.

\section{Paula Gaviria Betancur ${ }^{1}$}

Para citar: Gaviria, P. (2018). Reflexiones para el diálogo. Comentarios al libro La Colombia del posacuerdo: retos de un país excluido por el conflicto armado. Ciudad Paz-ando, 11(2), 97-99. doi: https://doi.org/10.14483/2422278X.14274

Fecha de recepción: 05 de noviembre de 2018

Fecha de aprobación: 01 de diciembre de 2018

En el marco del lanzamiento del libro: La Colombia del posacuerdo: retos de un país excluido por el conflicto armado, en agosto de este año, compartí unos breves comentarios sobre el mismo y sobre por qué considero que la apuesta colectiva, el programa de investigación del que hace parte este libro es muy buena noticia para el país.

Lo primero que pude constatar es que el libro cumple con el objetivo de los editores de ofrecer miradas multidimensionales sobre un modelo de sociedad posible tras la firma del Acuerdo Final entre el gobierno y las FARC-EP; sobre la manera en que asumimos el reto de construir la paz y de tramitar pacíficamente los conflictos connaturales a cualquier sociedad.

El libro es también evidencia de una academia comprometida con dar a la ciudadanía elementos de reflexión en ese tránsito hacia un país más consciente de su pasado, dueño de su presente y arquitecto de su futuro. Nos brinda análisis, enfoques variados, recomendaciones y pautas para concienciarnos de que aquella paz es también nuestra y, por tanto, su desarrollo y consolidación nos incumbe a todos.

Aciertan los editores cuando sugieren recorrer el libro como una búsqueda - iy no cualquier búsqueda! -, porque se trata de encontrarnos sin la excusa del conflicto armado con esa guerrilla, pero también de entendernos a partir de él; se trata de vernos en el espejo y reconocernos en el otro; de saber mirar hacia atrás con vergüenza y dignidad a la vez y, sobre todo, de mirar hacia adelante y soñar, como dicen los editores, con una paz estable y duradera.

Los textos se nutren de un trabajo ambicioso y completo sobre las teorías del conflicto armado en Colombia, las perspectivas multidimensionales de la paz, las implicaciones de dejar atrás la guerra y las tareas que quedan para eso que llamamos el "posacuerdo".

1 Consultora en derechos humanos y derechos las víctimas. Dirigió la Unidad para la atención y reparación a las víctimas y fue Consejera Presidencial para los derechos humanos. Correo electrónico: gaviria.paula@gmail.com 
No obstante, el verdadero valor de esta obra radica en su convicción sobre las oportunidades que se abren en esta etapa, sin olvidar a los actores que ahora aparecen o reaparecen, las tensiones que rodean al modelo de acuerdo alcanzado y el desafío de recomponer el tejido social. ¿Qué nación estamos dispuestos a construir, sin exclusiones, divisiones ni fragmentaciones?

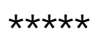

Este ambicioso proyecto agrupa el trabajo de 41 investigadores de distintas trayectorias académicas, investigativas y disciplinares que logran presentarnos una diversidad de escenarios, situaciones y actores sobre los que se requiere reflexionar pero también actuar para garantizar que el camino del posacuerdo por el que transitamos nos conduzca a los cambios pendientes que requiere nuestra democracia.

El libro se estructura en cinco grandes bloques. En mi caso, opté por una lectura no secuencial que me llevó a identificar factores comunes y relaciones entre los análisis y temáticas presentados.

Un primer eje común, tal vez el principal, es la importancia de la participación de la sociedad en la construcción de su futuro y, particularmente, de las víctimas y aquellos que han sido despojados de su ciudadanía y deshumanizados por la violencia, la indiferencia y la exclusión. Los capítulos 1, Marisol Raigosa y Alba Cruz y 2, Marcela Gaitán, Luz Sarmiento y Lucas Uribe, realizan un abordaje serio y sistemático de esta problemática.

Era impensable que una negociación dirigida a poner fin al conflicto con las FARC-EP y sentar las bases para la construcción de una paz estable y duradera no contara con las voces y propuestas de la sociedad civil y de los sobrevivientes. Ello, por dos razones: en primer lugar, porque la población también es parte del conflicto en tanto recibe sus impactos y, en segundo lugar, por el rol histórico de las organizaciones sociales en el largo y doloroso camino de buscar una salida negociada a tantos años de guerra.

Así, el texto de Mauricio Calbet, nos muestra un análisis riguroso sobre la participación social en la Mesa de Conversaciones, que revela la efectiva incidencia de las propuestas de la ciudadanía en el Acuerdo. Se cumplió, en consecuencia, el objetivo de reconocimiento y dignificación planteado por los negociadores con los mecanismos de participación.

Este es, tal vez, el primer paso para la reconstrucción del tejido social: reconocer una ciudadanía de la cual muchos colombianos han sido históricamente despojados, y cuyo poder de transformación es mayor cuando intervienen en procesos sociales y colectivos organizados.

Y es que estos colectivos, deben ser estudiados más allá de sus aportes a las problemáticas derivadas de la guerra o de sus esfuerzos para la solución. Las experiencias que ha desarrollado la sociedad civil organizada van desde temas de protección, defensa de derechos y resistencia frente a la violencia, hasta reintegración de excombatientes, atención a víctimas y desarrollo, entre muchos otros.

Por ello, resultan muy significativos los capítulos dedicados a procesos sociales impulsados desde las comunidades, como el estudio de Karen Betancourt, José Foncillas y Freddy Guerrero sobre las prácticas de memoria en Tumaco (Nariño), o la experiencia resaltada por Erika Ramírez y Camila Gómez, quienes nos hablan del poder de las resistencias en el caso del pacto de paz de los indígenas de Gaitania (Tolima), y el caso de los grupos ambientales juveniles en Leticia (Amazonas), indagado por Emilmar Rodríguez, Douglas Molina y Ana Molina.

La movilización de esta sociedad civil, como lo sugiere el capítulo de Mauricio Hernández y Jaime Wilches, deberá hacerse ya no entre pares e iguales, sino con los indiferentes, los excluidos... Allí, según el trabajo de Laura Ramírez, la Iglesia tiene un rol fundamental en evitar la polarización. ¿Vino entonces el Papa Francisco a Colombia en el 2017 a eso, a unirnos?

Un pasaje del Papa reseñado por la autora nos expone varios elementos para reflexionar:

\section{"Yo prometo que cuando este acuerdo sea blindado por el plebiscito y obtenido el reconocimiento internacional, yo iré a Colombia para enseñar la paz".}

En su momento, se trató de una declaración polémica del pontífice pues contrastaba con la postura de la Conferencia Episcopal que se limitó a invitar al pueblo colombiano a participar de manera informada y a conciencia. Una posición vista como neutra por muchos, por otros como inconsecuente con la doctrina y pastoral social de la iglesia y para la autora como una decisión respetuosa del estado laico que es Colombia desde la Constitución Política de 1991.

Ramírez expone las razones por las que la visita del Papa Francisco fue altamente política, no solo por el contexto nacional: un país polarizado después del plebiscito, con escándalos de corrupción y un ambiente de creciente descontento frente a los avances en la implementación de lo acordado. La visita es política precisamente por la trayectoria de la Iglesia en la búsqueda de una salida negociada al conflicto y su apoyo a las víctimas y a la reconciliación. Para la autora del texto sobre la visita del Papa a Colombia, el acto del Papa en Villavicencio, con testimonios de sobrevivientes y la presencia del Cristo mutilado en la masacre de Bojayá, es el ejercicio de memoria histórica y de comunicación masiva con más poder simbólico que se haya efectuado para las víctimas en el país.

Al respecto, resulta interesante ver cómo algunos textos del libro también cuestionan el rol de los medios de comunicación en la cobertura de las negociaciones, el 
plebiscito y el posacuerdo. Según algunos autores a dos años del Acuerdo Final, sigue primando la retórica del periodismo de guerra.

Por ello, José Manuel Rivas desde el estudio de los liderazgos de Uribe y Santos, Nathalia Bonilla con el abordaje de los imaginarios políticos construidos por los medios masivos de comunicación e Irene del Mar con el análisis de los memes como ejes articuladores en las representaciones sociales de la realidad, se preguntan sobre el resultado del plebiscito del 2 de octubre de 2016. ¿Se falló en la pedagogía y la comunicación por parte de estas experiencias? ¿Cómo llegar entonces a quienes no están organizados y a los indiferentes? ¿Cuál debe ser el trabajo de esta sociedad civil organizada en el posacuerdo?

En esa línea, el apartado sobre conflicto armado y cine, escrito por Martín Agudelo, nos recuerda que el séptimo arte sí ha mostrado lo que instancias de poder han querido mantener invisible: una cierta amnesia colectiva y una clara indiferencia hacia el dolor. Es un cine que se ha puesto en el lugar de la víctima, que ha reconocido su sufrimiento a través de protagonistas que se resisten a renunciar a sus sueños y que han encontrado maneras de afrontar su pasado y sobrevivir. El autor de este texto nos dice sin anestesia que tenemos que aceptar nuestra responsabilidad por el horror vivido en Colombia y el padecimiento de las víctimas.

Así, el cine representa una posibilidad única para confrontar nuestras miserias, pero también, mediante la memoria colectiva, para lograr el compromiso de la sociedad con la inclusión de las víctimas y la no repetición de los hechos.

Finalmente, el libro aborda otras temáticas esenciales, como las transformaciones del Estado, la recuperación de su legitimidad y la necesaria y pendiente transformación del campo. Para esto, resulta clave el texto de Gina Paola Rico y Leslie Hossfeld sobre los cambios críticos de la ruralidad y los desafíos institucionales para construcción de un modelo económico incluyente. Este último tema tal vez es el más determinante de la apuesta de transformación que trae el Acuerdo de Paz para efectivamente lograr enfrentar las causas estructurales de la violencia y la desigualdad. Según el mismo, la reforma rural integral contribuirá a la transformación estructural del campo, cerrando las brechas entre campo y ciudad, integrando regiones, promoviendo la igualdad y asegurando el bienestar de los campesinos y campesinas.

También merecen una reflexión profunda los capítulos de Javier Torres sobre el mantenimiento de las condiciones de control y presencia territorial del Estado, y en el caso del texto de Miguel López, sobre los retos en la administración de justicia y con un enfoque pensado en las víctimas y el desplazamiento forzado; o el análisis del contexto geopolítico que presentan Eugenia Vega y Hadrien Lafosse, en el que valoran las capacidades de Colombia en el posacuerdo para convertirse en líder regional en políticas públicas, económicas, comerciales, de derechos humanos y en torno a la construcción de paz.

El proyecto editorial que comprende los libros: "Teorías y tramas del conflicto armado en Colombia", "Esta guerra que se va. Territorio violencias; desigualdad y fragmentación social" y "La Colombia del Posacuerdo: retos de un país excluido por el conflicto armado", es un primer paso en la dirección correcta.

Los docentes, investigadores, editores y las universidades que hacen parte de esta comunidad académica en la que se convirtió este ambicioso proyecto de investigación, liderado por la Universidad Distrital, asumieron que la academia sí tiene un rol determinante en la comprensión de lo que nos ha pasado como nación pero sobre todo en ofrecer reflexiones sobre qué tipo de sociedad queremos ser en el posacuerdo, qué tipo de conversaciones debemos sostener y con quiénes. De lo que se trata es de no seguir excluyendo a ese otro que finalmente habla de nosotros mismos y de nuestra identidad como país. De ahí la importancia de los textos que trae el libro pues integra en los análisis, el rol del sector privado, los medios de comunicación, el territorio entre otros.

Como señalan varios autores, el posacuerdo ya no es una posibilidad, sino que forma parte de nuestra realidad cotidiana. Es el momento de que decidamos, sin más dilaciones, el proyecto de país presente y futuro en el que deseamos vivir. En buena hora, contamos para ello con un insumo fundamental por parte de la academia. Nos corresponde continuar la reflexión involucrando al resto de la sociedad.

\section{(9) $(\Theta \odot)$}

